\title{
Indicadores de atitude de estudantes e professores com relação à matemática
}

\author{
Paulo Cézar de Faria ${ }^{1}$ \\ Universidade Federal do Rio Grande do Norte, Natal-RN, Brasil \\ Brigido Vizeu Camargo \\ Universidade Federal de Santa Catarina, Florianópolis-SC, Brasil \\ Maria Lucia Faria Moro \\ Universidade Federal do Paraná, Curitiba-PR, Brasil
}

\begin{abstract}
Resumo: O estudo compara a atitude em relação à matemática de quatro grupos amostrais de estudantes de licenciatura em matemática e de professores de matemática em exercício. Os participantes $(n=440)$ foram voluntários de escolas públicas e privadas escolhidas por conveniência. O referencial teórico se reportou ao construto atitude. Indicadores das razões de escolha do curso superior, dos fatores que dificultam o ensino da matemática e das razões que levam a lecionar matemática foram revelados por meio do uso de instrumentos que forneceram dados de natureza qualitativa. A condição em que a pessoa se encontra no final da licenciatura e no início da carreira, associada à sua autopercepção de desempenho, indica que a mudança de atitude está relacionada às particularidades de um determinado momento da vida estudantil ou profissional. Os resultados sublinham a importância de utilizar diferentes instrumentos para se obter indicadores de atitude com relação à matemática.
\end{abstract}

Palavras-chave: atitudes do estudante, atitudes do professor, matemática, formação profissional.

\section{Indicators of students' and teachers' attitude towards mathematics}

\begin{abstract}
The study compares the attitude of four sample groups of mathematics students teaching and mathematics teachers towards mathematics. The participants $(n=440)$ were volunteers from public and private schools chosen by convenience. The theoretical model refers to the construct attitude. The instruments used provided qualitative data about participants' reasons for choosing higher education, factors that hinder the teaching of mathematics and reasons they chose to teach mathematics. The person's condition at the end of the teaching program and at the beginning of career coupled to the self-perception of performance indicates that the change of attitude is related to the particularities of a given moment of the student or professional life. Results highlight the importance of using a variety of instruments to obtain indicators of attitudes towards mathematics.
\end{abstract}

Keywords: student attitudes, teacher attitudes, mathematics, professional education.

\section{Indicadores de actitud de estudiantes y maestros respecto a las matemáticas}

Resumen: El estudio compara la actitud con respecto a matemática de la muestra de cuatro grupos de estudiantes de licenciatura y maestros en ejercicio. Los participantes $(n=440)$ eran voluntarios de las escuelas públicas y privadas elegidos por conveniencia. El modelo teórico se replicó en el constructor de actitud. Se encontraron indicadores de las razones de elección del curso superior, de los factores que dificultan la enseñanza y de las razones que llevan a la docencia, mediante el uso de instrumentos que suministraron datos de naturaleza cualitativa. La situación en que la persona se encuentra al final de la licenciatura y al inicio de carrera, asociada a su percepción del desempeño, indican que el cambio de actitud está relacionado con las particularidades de un momento en la vida estudiantil o profesional. Los resultados muestran la importancia de utilizar diferentes instrumentos para obtener indicadores de actitud con respecto a las matemáticas.

Palabras clave: actitudes del estudiante, actitudes del profesor, matemática, formación profesional.

O conceito de atitude, do campo da Psicologia Social, é central para o presente trabalho. Conforme Doise (2000), desde os anos 1930, a concepção geral de atitude e seu método de estudo pressupõem referência à posição que o indivíduo toma diante de um objeto considerando uma ou várias das suas dimensões, resultando numa avaliação deste último. O interesse da Psicologia Social pelos estudos de atitude, segundo Rodrigues (1981), deveu-se a três pontos: (a) as atitudes são bons preditores do comportamento; (b) elas nos ajudam a organizar cognitivamente a realidade em que vivemos; e (c) são base para as relações de amizade, participação e filiação grupal.

Eagly e Chaiken (1993) esclarecem que as atitudes não podem ser diretamente observáveis, pois estão relacionadas

1 Endereço para correspondência:

Prof. Dr. Paulo Cézar de Faria. Rua Dona Maria Câmara, 1988. CEP

59082-430. Natal-RN, Brasil.E-mail: paulocezar@ccet.ufrn.br à predisposição que uma pessoa tem para avaliar um determinado objeto, seja aprovando-o ou desaprovando-o. Desse modo, as atitudes se reportam à categoria dos construtos aquilo que é elaborado ou sintetizado com base em dados simples, um conceito - podendo ser inferidas com base em respostas avaliativas que o sujeito emite em relação ao objeto da atitude, tendo como suporte componentes cognitivos, afetivos e conativos.

A atitude dos professores em relação à matemática, entendida como o posicionamento avaliativo global dos mesmos em relação a este objeto, ao possibilitar predições do comportamento frente a este objeto, certamente traz grande interesse para a compreensão dos problemas relacionados ao ensino desta disciplina. Supõe-se que uma atitude negativa em relação à matemática possa estar relacionada a interferências negativas no seu ensino e na sua aprendizagem.

Neste estudo, procurou-se contemplar os atributos 
essenciais do conceito de atitude e as relações entre eles, considerando que "atitude poderia ser definida como uma disposição pessoal, idiossincrática, presente em todos os indivíduos, dirigida a objetos, eventos ou pessoas, que assume diferente direção e intensidade de acordo com as experiências do indivíduo" (Brito, 1996, p. 11). Com esse enfoque, o presente trabalho estuda as atitudes em relação à matemática, esta enquanto ciência.

A medida da atitude representa uma parte bastante significativa no estudo científico desse construto. A possibilidade de inferir a atitude a partir de qualquer expressão de comportamento que reflita um de seus componentes impulsionou estudos que buscaram a criação de técnicas para a mensuração das atitudes, as chamadas escalas de atitudes (Likert, 1932).

Vale destacar ainda a importância do uso de diversos indicadores para se avaliar atitude, cuja congruência deve ser observada. Um aspecto especialmente analisado neste estudo são os méritos e as conveniências do uso de diversos instrumentos, bem como a congruência dos resultados por eles revelados e sua contribuição para avaliar a atitude com relação à matemática.

O pressuposto de que uma atitude negativa em relação à matemática pode interferir negativamente no seu ensino e na sua aprendizagem permite a seguinte conjectura: uma atitude negativa em relação à matemática, presente na atividade docente, pode contribuir negativamente no processo de aprendizagem dos alunos, gerando nesses últimos, reações emocionais negativas em relação às situações didáticas em que estão envolvidos.

Nesta perspectiva o trabalho apresentado por Gonçalez e Brito (2001) indica que professores com atitude positiva em relação à matemática encorajam seus alunos à independência, possibilitando-lhes o desenvolvimento do raciocínio e das habilidades básicas para a resolução de problemas matemáticos. Ao contrário, professores com atitude negativa podem tornar seus alunos dependentes, pois a única fonte de conhecimentos é frequentemente o professor. Nessa linha, alguns estudos (Shiomi, 1992; Randel, Stevenson, \& Witruck, 2000; Viana, 2005; Dobarro, 2007) indicam que a atitude em relação à matemática tem efeitos importantes sobre o comportamento, o desempenho e a autoeficácia do estudante ao longo das séries.

De modo geral, a busca de compreensão a respeito da influência do professor na promoção de atitude negativa acerca da matemática se enquadra no conjunto de estudos que se referem às suas crenças, atitudes, valores, concepções, ansiedade, afeto, percepções, expectativas e tipo de relação que ele mantém com o aluno, seja diretamente ou por meio da metodologia de ensino adotada (Brito, 1996; García, 1999; Trillo, 2000; Silva, Brito, Cazorla, \& Vendramini, 2002; Zan, Brown, Evans, \& Hannula, 2006).

A compreensão de que as atitudes não são estáveis, e muito menos cristalizadas (Brito, 1996), pressupõe que o currículo dos cursos de formação de professores de matemática deva ser estruturado com base em diferentes possibilidades de apreensão de conhecimentos no sentido de promover o desenvolvimento de uma atitude positiva em relação a ela.

Entretanto, em estudo desenvolvido por Faria (1996) foi constatado que essa atitude em relação à matemática não é uma dimensão trabalhada nos cursos de formação docente. Além disso, a experiência pessoal do primeiro autor deste artigo com a formação de professores permite supor que situações favoráveis a uma atitude positiva em relação à matemática podem não ser vivenciadas na formação inicial do professor, e tampouco podem ser inferidas das ações que esses manifestam em cursos de formação continuada. Esse problema apresenta interesse investigativo na medida em que a ausência de uma atitude positiva em relação à matemática pode acarretar consequências desfavoráveis à formação do professor e ao exercício da docência.

As considerações precedentes, os resultados obtidos em estudo anterior (Faria, 1996) e a experiência adquirida no trabalho desenvolvido pelo primeiro autor com professores oriundos de todas regiões do Brasil, possibilitaram a formulação da seguinte hipótese: tanto as atitudes dos professores de matemática em formação como a dos professores em exercício, são negativas em relação à matemática. $\mathrm{O}$ objetivo da presente investigação foi o de verificar a consistência desta hipótese.

Para fins de direcionamento do estudo, foram especificadas as seguintes questões: (a) professores de matemática em formação e já em exercício apresentam diferenças em suas atitudes em relação à matemática? (b) há diferenças nas atitudes em relação à matemática dos alunos do início da licenciatura, quando comparados com aqueles que estão no final da licenciatura deste curso? (c) as atitudes em relação à matemática dos professores em exercício se modificam no transcorrer da atividade profissional?

\section{Método}

\section{Participantes}

Este estudo pautou-se na técnica de levantamento de dados em uma perspectiva comparativa e de corte transversal. A presença do fenômeno - atitude em relação à matemática - foi comparada em quatro grupos amostrais compostos por participantes voluntários de instituições escolares escolhidas por conveniência. O Grupo 1 foi constituído por alunos do início do curso de licenciatura em matemática (185 participantes). Já o Grupo 2 foi constituído por alunos do final do curso de licenciatura em matemática (69 participantes). O Grupo 3 foi composto por professores de matemática com um a dez anos de experiência (156 participantes), enquanto o Grupo 4 foi formado por professores de matemática com mais de dez anos de experiência (30 participantes).

\section{Instrumentos}

No presente estudo foram utilizados os seguintes instrumentos: autobiografia, questionário, escala de atitudes tipo Likert e entrevistas. 
Faria, P. C., Camargo, B. V., \& Moro, M. L. F. (2009). Indicadores de atitude com relação à matemática.

A autobiografia se caracteriza pela produção de um relato escrito, por meio do qual o sujeito pode expor seu conhecimento, seus sentimentos e suas ações em relação ao objeto de estudo, que no caso é a matemática. O uso deste instrumento possibilitou encontrar no registro escrito indicadores relevantes que explicitaram as relações do participante com a matemática, no percurso de sua vida escolar, por meio dos quais foi possível inferir sua atitude em relação a esta ciência.

O questionário utilizado permitiu caracterizar os participantes por meio de dados pessoais e profissionais. A partir desse instrumento foi possível conhecer: a razão pela qual o participante escolheu certo tipo de curso superior; o grau de importância por ele atribuído à formação continuada; suas preferências em relação ao ensino de determinados conceitos matemáticos e as dificuldades que encontrou no ensino da matemática. O questionário continha questões abertas por meio das quais foi possível verificar se os três componentes que caracterizam a atitude (afetivo, cognitivo e conativo) em relação à matemática eram explicitados.

A Escala de Atitudes em Relação à Matemática, utilizada neste estudo, foi adaptada e validada por Brito (1998). Por meio deste instrumento, o participante deve emitir uma resposta a cada um dos itens que compõe a escala. As respostas variam de uma plena concordância até uma total discordância. A escala possui 20 itens (10 positivos e 10 negativos) cuja finalidade é medir as atitudes dos respondentes em relação à matemática. Além disso, os itens 21 e 22 foram incluídos com o intuito de verificar a autopercepção do indivíduo e as razões que o levaram a dar aulas de matemática, respectivamente. A possibilidade de mensuração oferecida pelas escalas de atitudes traz maior precisão e validade aos resultados obtidos. A escolha deste instrumento foi importante para a realização da pesquisa ao permitir identificar os graus de aceitação ou rejeição dos participantes em relação à matemática, logo, o tipo de atitude que eles apresentavam em relação à matemática.

A entrevista é uma das técnicas de coleta de dados que permite obter informações, por exemplo, sobre compreensões, sentimentos e ações que as pessoas têm acerca de diversas situações. Por meio da análise dos relatos orais dos entrevistados estabeleceu-se uma correspondência entre as estruturas semânticas - entendidas aqui como representação do sentido dos enunciados - e os componentes que caracterizam as atitudes - afetivo, cognitivo e conativo - dos participantes em relação à matemática. Verificou-se em que medida aqueles três componentes se explicitam por meio de alguma resposta observável ou comportamento manifesto em uma entrevista do tipo semiestruturado com roteiro previamente elaborado.

Em vista da complexidade do fenômeno estudado (atitude em relação à matemática), procuramos não somente medir as atitudes dos participantes em relação à matemática, mas, também, melhor compreender a natureza da atitude com relação à ciência matemática. Em consequência da existência de vários componentes do construto e da definição de atitude aqui assumida, empregamos então, não apenas uma avaliação quantitativa, por meio de uma escala, mas, combinada a ela, uma avaliação qualitativa a fim de, especialmente com esta, obtermos outros indicadores que permitissem inferir a natureza da atitude com base em respostas avaliativas.

\section{Procedimento}

Os participantes receberam esclarecimentos sobre as intenções da investigação e sobre os instrumentos que seriam utilizados, estavam cientes de que o acesso a seus dados pessoais estaria restrito ao pesquisador - que se responsabilizou pela sua não divulgação - e que todas as análises seriam realizadas sem sua identificação. Os sujeitos consentiram em participar do estudo e demonstraram concordância com os objetivos e procedimentos adotados. No momento da realização do estudo todos os cuidados éticos foram observados, inclusive o consentimento formal dos entrevistados e das escolas.

O estudo foi subdivido em duas fases de coleta de dados. Na primeira fase foram aplicados três instrumentos, na seguinte ordem: autobiografia, questionário e escala de atitudes tipo Likert (Brito, 1998). Estes instrumentos foram aplicados a todos os participantes $(n=440)$ em momentos e ambientes diferenciados.

Na segunda fase de coleta de dados, em função do escore obtido na escala de atitudes em relação à matemática, somente dez participantes foram entrevistados. Foram escolhidos os cinco que obtiveram os mais baixos escores na escala, logo com atitudes mais negativas; e também os cinco que tiveram escores mais altos, logo com atitudes mais positivas. As entrevistas foram realizadas pelo primeiro autor deste artigo. Todos participantes foram entrevistados individualmente, em ambientes diferenciados. Todos os procedimentos de coleta de dados foram previamente testados em estudo piloto.

\section{Análise dos dados}

Os dados coletados por meio da escala de atitudes foram submetidos a testes estatísticos para examinar o significado das tendências encontradas. Para tratar estatisticamente os dados foi empregado o programa SPSS (Statistical Package for the Social Sciences - versão 12.0). Os procedimentos estatísticos serviram para o teste estatístico da sustentabilidade da hipótese e para comparação das atitudes de cada um dos grupos amostrais.

O questionário utilizado compôs-se de questões de múltipla escolha e questões abertas, a maior parte delas solicitava respostas de natureza quantitativa. Essas respostas foram analisadas por meio da estatística descritiva, utilizamos para isso novamente o programa SPSS.

Os dados fornecidos pela autobiografia, e também pelas questões abertas presentes em outros dois instrumentos são de natureza qualitativa. Para analisar estes dados utilizamos o programa ALCESTE (Analyse Lexicale par Contexte d'un 
Ensemble de Segments de Texte - versão 4.5). O uso desse recurso tecnológico permitiu identificar padrões, tendências e motivos de aceitação ou rejeição à matemática. Esse programa agrupa os dados conforme a lista de palavras oriundas dos relatos escritos, permitindo a leitura e a interpretação dos referidos relatos por meio de análises mais refinadas. Para tanto, ele busca quantificar um texto para extrair suas estruturas significantes mais fortes. As estruturas estão estreitamente ligadas à distribuição de palavras num texto e a distribuição raramente acontece de maneira aleatória. O interesse pela utilização do ALCESTE está ligado à possibilidade de descrever, classificar, assimilar e sintetizar automaticamente dados textuais, com vistas a descobrir a informação essencial contida num texto.

Algumas regras específicas foram seguidas na preparação do material textual conforme indicações de Camargo (2005). Um conjunto de unidades de contexto iniciais (UCIs) constitui o corpus de análise. O corpus adequado à análise do ALCESTE deve constituir-se num conjunto textual centrado em um tema. Trabalhamos com quatro corpi, pois havia três respostas abertas e a autobiografia. Para efetuar a análise do material textual, o software utiliza o método de classificação hierárquica descendente (CHD). Esse método permite a localização das oposições mais fortes entre as palavras do texto e extrai, em seguida, as classes representativas dos enunciados em função da semelhança entre as unidades de contexto elementar (u.c.e.). "A descrição do conteúdo do texto é feita por meio das palavras associadas a cada classe e do contexto de ocorrência das mesmas, ou seja, das UCE características de cada uma das classes obtidas" (Giacomozzi \& Camargo, 2004, p. 35).

Assim, por intermédio dos relatos escritos, procuramos verificar se os três domínios que caracterizam as atitudes (afetivo, cognitivo e conativo) dos participantes para com a matemática se tornaram explícitos. Os dados colhidos pelas entrevistas foram registrados de acordo com a expressão oral dos participantes, gravadas em áudio e pelos registros escritos do entrevistador. Com a intenção de tornar explícito o conteúdo das mensagens emitidas recorremos ao terreno da análise de conteúdo conforme a perspectiva adotada por Bardin (1977). Para conhecermos o sentido do texto e garantir a possibilidade de interpretação dos dados mediante a análise de conteúdo, os requisitos de objetividade e de sistematização foram observados e permitiram inferências sobre os elementos da comunicação.

\section{Resultados}

Da análise estatística dos resultados provenientes da medida de atitudes, manifestaram-se diferenças nos grupos amostrais. Uma diferença significativa se mostrou na comparação entre alunos do início da licenciatura e professores em exercício. Assim, obtivemos indícios de que as atitudes em relação à matemática se modificam durante a formação inicial e também no transcorrer da atividade profissional.
Por meio do programa ALCESTE foi possível tratar os conteúdos das respostas textuais obtidas sob o ponto de vista qualitativo, para depois verificar sua incidência quantitativamente. Após a submissão dos dados ao referido programa, iniciou-se a análise dos resultados apresentados pelos quatro corpi.

O corpus 1 tomou como referência o tema envolvido na questão 10 do referido questionário (Aponte a razão pela qual escolheu esse curso superior). A Figura 1 expressa o resultado das classificações hierárquicas descendestes e ilustra as relações interclasses.

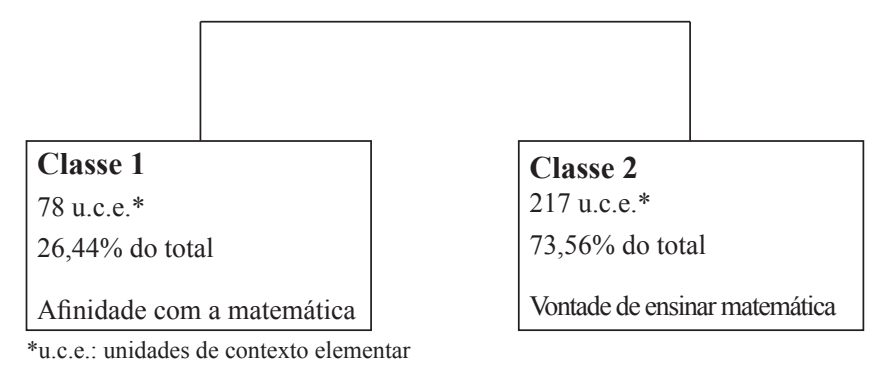

Figura 1. Análise hierárquica descendente corpus 1: razões de escolha do curso superior.

O corpus 1 foi subdividido, obtendo-se as classes $1 \mathrm{e}$ 2. A classificação hierárquica descendente foi concluída com apenas uma partição, pois as duas classes mostraram-se estáveis, ou seja, são compostas por unidades de contexto elementar (u.c.e.) com vocabulário semelhante. A análise descritiva do vocabulário característico da classe 1 revela que esta se organiza através de oito elementos: afinidade, exatas, ciência, cálculo, campo, aptidão, maior e profissional. $\mathrm{O}$ verbo ter também faz parte do vocabulário característico dos participantes que compõem a classe 1 .

Pela leitura dos extratos das listas de unidades de contexto elementar selecionados na classe 1 , revela-se a afinidade que esses participantes apresentam com a matemática. Eles demonstram maior aptidão pelas ciências exatas e têm um bom relacionamento com a disciplina em questão. A facilidade com os cálculos impulsionou esses participantes a escolher a matemática, ou outro curso da área de exatas, como campo profissional. A razão de escolha também se deu pelo fato de ser este um campo profissional bastante amplo, o que possibilita maior facilidade de inserção no mercado de trabalho.

Essas características conduzem à seguinte afirmação: esses participantes avaliam favoravelmente o objeto da atitude (a matemática), pois é possível perceber que eles tendem a se envolver com situações que favorecem e valorizam esse objeto. Esses resultados permitem observar traços dos componentes da atitude em relação à matemática. Nos relatos escritos esses participantes expressaram uma avaliação positiva a respeito, o que permite supor que apresentam atitude positiva em relação à matemática. 
A análise descritiva do vocabulário característico da classe 2 revela que ela se organiza através de três elementos: matemática, professor e vontade (substantivos). Os verbos gostar, ensinar e querer também fazem parte do vocabulário característico dos participantes que compõem a classe 2. A leitura dos extratos desta classe indica que o foco está centrado na vontade de ensinar matemática. $\mathrm{O}$ fato de gostar da matemática e a vontade de aprender impulsionaram esses participantes a optar pela licenciatura neste curso. Por outro lado, o fato de gostar de trabalhar com o público e o de ter aprendido a gostar da matemática, no decorrer de sua experiência acadêmica, contribuíram para a escolha deste curso superior.

Nota-se que os participantes pertencentes à classe 2 também avaliaram favoravelmente o objeto da atitude. É provável que eles tenham vivenciado sentimentos e emoções que os levam a reagir de maneira positiva em relação à matemática. Esses resultados permitem observar indícios dos componentes da atitude e supor que eles contribuem para a formação de uma atitude positiva em relação em relação à matemática.
Em síntese, os resultados da análise do corpus 1 apontam que, para a amostra de professores com um a dez anos de experiência, a razão de escolha do curso superior foi a afinidade com a matemática. Eles manifestaram aptidão por ciências exatas, facilidade com cálculos e acreditaram ser esse um campo profissional promissor. Já a amostra de alunos iniciantes do curso de licenciatura manifestou que as razões de escolha estavam relacionadas com a vontade de ensinar matemática, com o gosto por essa área do conhecimento e também com a vontade de aprender sobre ela. Essas razões de escolha do curso superior revelam uma avaliação favorável do objeto da atitude, constituindo-se em marcas ligadas à atitude positiva em relação à matemática.

O corpus 2 tomou como referência o tema envolvido na questão 26 do referido questionário (Fator que mais contribui para a dificuldade encontrada ao ensinar matemática). A Figura 2 apresenta o resultado das classificações hierárquicas descendentes e ilustra as relações interclasses.

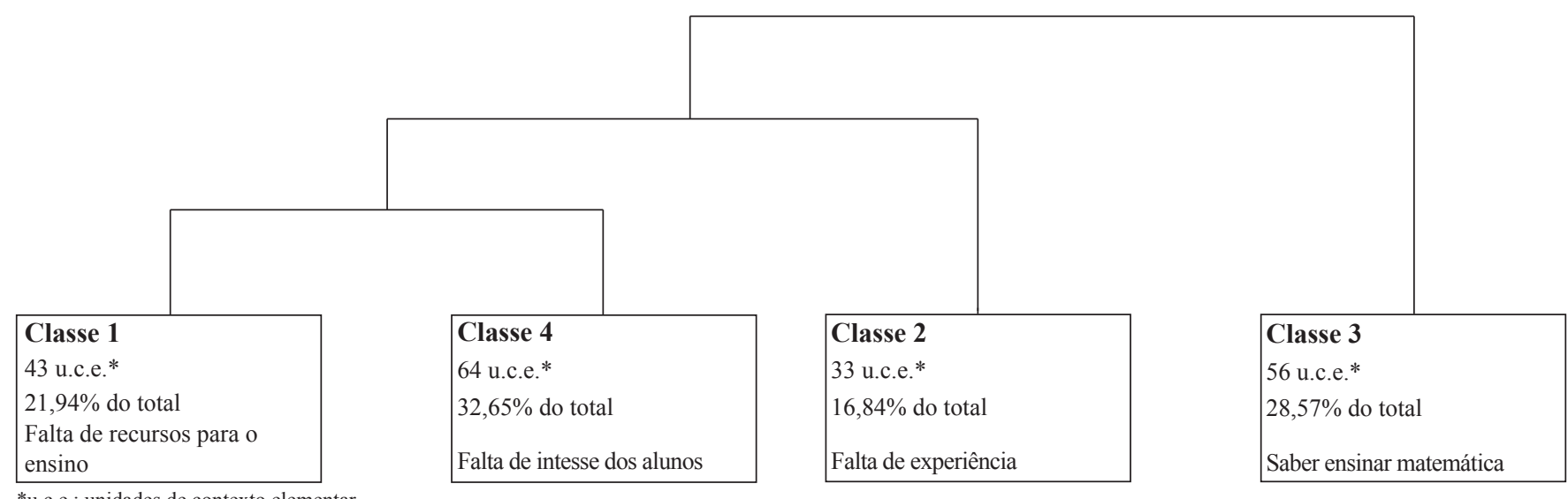

*u.c.e.: unidades de contexto elementar

Figura 2. Análise hierárquica descendente corpus 2: fatores que dificultam o ensino da matemática.

Foi possível obter o vocabulário mais significativo para cada uma das classes que compõem o corpus 2 . A classe 1 se organiza através de seis elementos: material, escola, recursos, didático, realidade e aprendizagem.

A leitura dos extratos das listas de unidades de contexto elementar selecionados na classe 1 indicou o foco na falta de recursos didáticos nas escolas e nas condições de trabalho. Há reclamações sobre a precariedade das escolas, a falta de material didático e a falta de uma metodologia adequada ao ensino da matemática. Além disso, são apontados: a marginalização dos jovens, a falta de base dos alunos, o tempo reduzido para vencer o conteúdo, a indisciplina, o desinteresse do aluno pelo conteúdo e a falta de experiência do professor como fatores que dificultam o ensino na matemática. Esses fatores podem contribuir para o desenvolvimento de atitudes negativas em relação à matemática.

Já a classe 4 se organiza através de três elementos: interesse, base e desinteresse. $\mathrm{O}$ verbo aprender também faz parte do vocabulário característico dos participantes que compõem essa classe. A leitura dos extratos mostra como foco a falta de interesse dos alunos. Esses participantes também alegam que a falta de base, a dificuldade de concentração, a falta de disciplina e a falta de vontade dos alunos em aprender são fatores que dificultam o ensino da matemática. Esses fatores podem contribuir para o desenvolvimento de atitudes negativas em relação à matemática.

A classe 2 se organiza através de seis elementos: aula, pré-requisito, experiência, série, relação e sala (substantivos). Os extratos das listas de unidades de contexto elementar selecionados indicam que o foco dessa classe está centrado na falta de experiência em sala de aula. Embora tenham feito estágio durante o curso de licenciatura, quando esses participantes iniciam a função docente eles sentem dificuldades para ensinar matemática. Alegam que o curso de graduação não foi suficiente para prepará-los adequadamente para a prática docente. Ao lado disso, as condições de 
trabalho não lhes permitem preparar adequadamente as aulas que irão ministrar.

Além disso, apontam as deficiências que os alunos trazem das séries anteriores (falta de pré-requisitos), a indisciplina, a falta de interesse e a falta de concentração, como fatores que dificultam o ensino da matemática. Diante disso é possível afirmar que esses fatores possam contribuir para o desenvolvimento de atitudes negativas em relação à matemática.

A classe 3 se organiza por meio de cinco elementos: ensinar, forma, pessoas, raciocínio e médio (substantivos). Os verbos trabalhar, saber, ter e passar também fazem parte do vocabulário característico dos componentes da classe 3. Os extratos das listas de unidades de contexto elementar indicam que o foco da classe está baseado no saber ensinar matemática. Para esses participantes, "saber" é diferente de "saber ensinar" e alguns deles manifestaram receio em não saber "passar o conteúdo" de forma clara e correta. Eles acreditam que os cursos de licenciatura formam bons matemáticos, mas péssimos professores, salvo raras exceções.

Dificuldades em explorar situações do cotidiano e representá-las por meio da linguagem matemática também foram apresentadas por esses participoantes como fatores que dificultam o ensino da matemática. Manifestaram ainda dificuldade em responder a perguntas do tipo: Para que serve isso que você está ensinando? Destacaram também a dificuldade em compreender a forma de raciocínio utilizada pelos alunos, e o que seria relevante para cada um deles aprender matemática. Diante disso é possível afirmar que esses fatores também contribuiriam para o desenvolvimento de atitudes negativas em relação à matemática.

Em suma, os resultados da análise do corpus 2 evidenciam que, para os professores com um a dez anos de experiência, os fatores que dificultam o ensino da matemática estão ligados a dois aspectos: econômicos, tais como, "a falta de recursos didáticos" e a "precariedade das escolas"; e sociais, tais como, "a marginalização dos jovens" e a "indisciplina dos alunos". Também cumpre papel preponderante nesses resultados a falta de experiência docente - associada notadamente a um estágio considerado insuficiente para a formação docente - e a falta de base e de concentração dos alunos. Por outro lado, os iniciantes do curso de licenciatura apontam a insegurança em relação à sua própria capacidade de saber ensinar como um fator que pode dificultar o ensino da matemática.

Os diversos fatores relacionados às dificuldades encontradas para ensinar matemática, manifestados por esses dois grupos de participantes, evidenciam uma avaliação desfavorável do objeto da atitude e correspondem a marcas ligadas à atitude negativa em relação à matemática.

$\mathrm{O}$ corpus 3 se refere às respostas ao item 22 da escala de atitudes (Cite a principal razão que levou você a dar aula de matemática). A Figura 3 expressa o resultado das classificações hierárquicas descendentes e ilustra as relações interclasses.

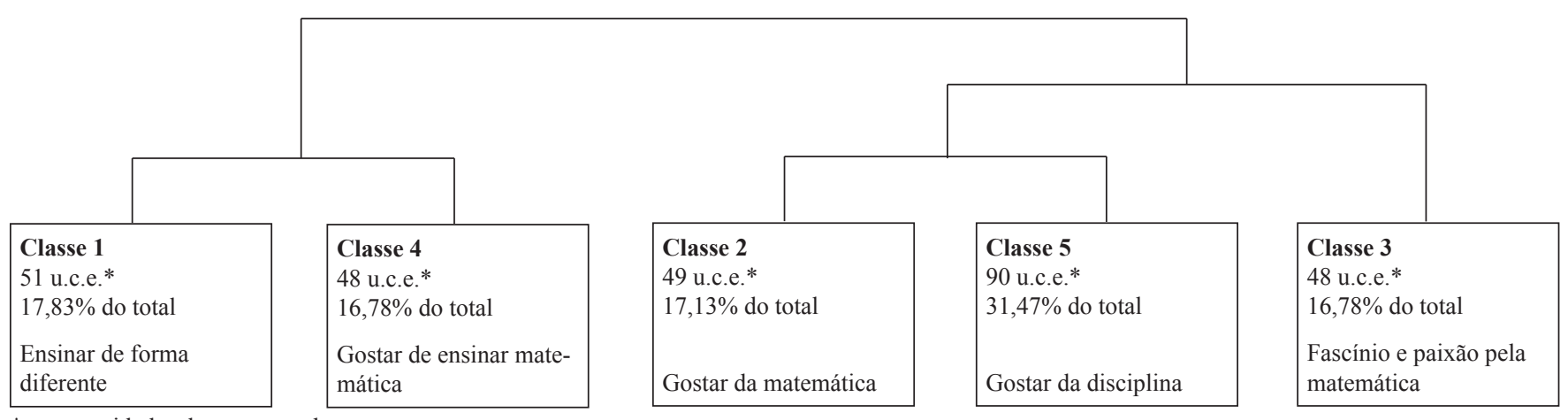

*u.c.e.: unidades de contexto elementar

Figura 3. Análise hierárquica descendente corpus 3: razões que levaram a lecionar matemática.

A classe 1 se organiza por meio de quatro elementos: interessante, diferente, mundo e vontade. Os verbos mostrar, aprender, ajudar, poder e tentar também são parte do vocabulário característico dos participantes que compõem a classe 1. A leitura dos extratos das listas de unidades de contexto elementar indicou que o foco volta-se para a vontade de ensinar a matemática de forma diferente. Nesses participantes percebemos interesse em gerar (nos seus futuros alunos) o entusiasmo pela matemática, em ensiná-la de forma divertida e interessante, mostrando que ela não é algo de "outro mundo" e que, ao contrário disso, é necessária e útil.

O fato de gostar de matemática impulsiona esses participantes a tentar mostrar às pessoas, principalmente às crianças, que elas podem aprendê-la. E, ainda, ao acender a "chama da matemática" em um aluno, consideram que é possível mudar o sentimento em relação a ela. A "paixão" que esses participantes têm pela matemática os estimula a querer ensiná-la de uma maneira diferente daquela utilizada pelos professores que tiveram.

Os argumentos utilizados para expor as razões que os levaram a lecionar matemática indicam uma avaliação favorável do objeto e, consequentemente, estariam contribuindo para a formação de uma atitude positiva em relação à matemática. Já a classe 4 se organiza através de quatro elementos: conhecimento, conteúdo, prazer e maior. Os verbos ter e transmitir também fazem parte do vocabulário característico desses participantes. Os extratos das listas de unidades de contexto elementar indicam que o foco está baseado no fato 
Faria, P. C., Camargo, B. V., \& Moro, M. L. F. (2009). Indicadores de atitude com relação à matemática.

de que eles sentem prazer em ensinar matemática. A paixão por essa área do conhecimento e a facilidade em ensinar levam esses professores a ter paciência com seus alunos, deixando-os mais à vontade em sala de aula, estimulando-os a estabelecer relações, a imaginar, a desenvolver o raciocínio, a buscar solução para uma situação proposta e a perceber a utilização da matemática na realidade em que estão inseridos.

Sentindo-se seguros com relação aos conteúdos que vão ministrar, eles gostam de ensinar e de ver o "brilho nos olhos dos seus alunos" quando adquirem um conhecimento matemático novo. Quando esses professores percebem que são capazes de ensinar e que o conhecimento de seus alunos está evoluindo, vivenciam um sentimento prazeroso em relação à matemática e ao seu ensino. Com base nessas características é possível afirmar que os indivíduos pertencentes à classe 4 avaliam favoravelmente a matemática, os julgamentos apresentados podem contribuir para a formação de uma atitude positiva em relação à matemática.

A classe 2 se organiza a partir de três elementos: fundamental, médio e faculdade. Os verbos lecionar e trabalhar compõem o vocabulário característico. Pela leitura dos extratos das listas de unidades de contexto elementar, vimos que o foco está no fato de que esses indivíduos gostam da matemática, possuem facilidade com cálculos e exercem outro trabalho relacionado a essa área do conhecimento fora do ambiente escolar.

Alguns participantes dessa classe, ao fazerem a opção por licenciatura em matemática, não imaginavam que gostavam de lecionar. A razão que os levou a dar aula estava ligada, em princípio, à falta de professores nessa área do conhecimento e à opção por lecionar como forma de aumentar a renda. Entretanto, as oportunidades que tiveram de ministrar aulas no ensino fundamental e médio, neles despertaram maior interesse pela matemática e pelo seu ensino.

Outros tiveram oportunidade de lecionar para os colegas que tinham dificuldades, enquanto estudavam no ensino fundamental e no médio. Outros, ainda, tiveram aula com excelentes professores de matemática. Esses motivos também foram citados como principais razões que os levaram a lecionar matemática. Assim, é possível afirmar que os participantes da classe 2 avaliam favoravelmente a matemática, o que pode contribuir para a formação de uma atitude positiva em relação à matemática.

Já a classe 5 se organiza por meio de dois elementos: a palavra disciplina (substantivo) e a contração "da". O verbo gostar também faz parte do vocabulário característico dos participantes que compõem a classe 5. Os extratos das listas de unidades de contexto elementar selecionados nesta classe sugerem estar o foco baseado no fato de que eles gostam de matemática, desde quando frequentavam o ensino fundamental e médio, e ainda continuam a apreciá-la no ensino superior. É a disciplina que preferem ensinar na escola, uma vez que se identificam com ela, tanto é assim que não conseguem imaginar-se dando aula de outra matéria.
São indivíduos que sempre admiraram seus professores de matemática e se identificam como docentes desta disciplina escolar porque têm facilidade em aprender e tiveram um bom desempenho durante a educação básica. Considerando esse contexto, é possível afirmar que os participantes da classe 5 também avaliam favoravelmente o objeto da atitude e as características apontadas por eles poderiam contribuir para a formação de uma atitude positiva em relação à matemática.

A classe 3 se organiza por meio de quatro elementos: fascínio, desafio, paixão e lógica (substantivos). Os verbos achar e apreciar também fazem parte do vocabulário característico dos participantes que compõem a classe 3. Pelos extratos constatamos que o foco dessa classe está baseado no fascínio e na paixão pela matemática. São indivíduos que apreciam a matemática porque ela é lógica, desafiadora, exige persistência, estimula o raciocínio e está presente em diversas situações. A paixão pela matemática foi a principal razão que os levou a dar aula. Eles têm facilidade em aprender esta disciplina, facilidade com o raciocínio lógico e com a linguagem matemática, acreditam que ela serve como suporte para o conhecimento científico e tecnológico.

Diante desses fatos, é possível afirmar que os participantes da classe 3 também avaliam favoravelmente o objeto da atitude. Os julgamentos apontados por eles podem contribuir para a formação de uma atitude positiva em relação à matemática. Observa-se que estes julgamentos estão mais diretamente relacionados ao objeto (a matemática per se) do que àqueles apontados pelos participantes das outras classes que compõem esse corpus.

Em síntese, os resultados da análise do corpus 3 permitem observar que os argumentos utilizados pelos iniciantes dos cursos de licenciatura sobre as razões que os levaram a lecionar (ou ao desejo de lecionar) revelam que eles estão dispostos a ensinar matemática de uma forma diferente, mostrando aos seus alunos (ou futuros alunos) que estes podem aprender. Já os argumentos utilizados pelos professores com um a dez anos de experiência estão ligados ao gosto, ao fascínio e à paixão que têm pela matemática como ciência e como disciplina escolar. $\mathrm{O}$ fato de terem tido aula com excelentes professores de matemática e o de terem tido um bom desempenho na educação básica foram apontados como razões que os levaram a lecionar. Além disso, o maior interesse pela matemática e pelo seu ensino aconteceu no momento em que começaram a lecionar. Eles afirmam ter facilidade em ensinar e sentem prazer ao observar que o aluno aprende.

As ligações que podem ser estabelecidas entre o desejo de lecionar e os sentimentos experimentados por esses dois grupos de participantes em relação à matemática, indicam uma avaliação favorável do objeto da atitude e correspondem a marcas ligadas à atitude positiva em relação à matemática.

O corpus 4 está relacionado ao tema abordado na autobiografia: Eu e a matemática. A Figura 4 apresenta o resultado das classificações hierárquicas descendestes e ilustra as relações intercalasses. 


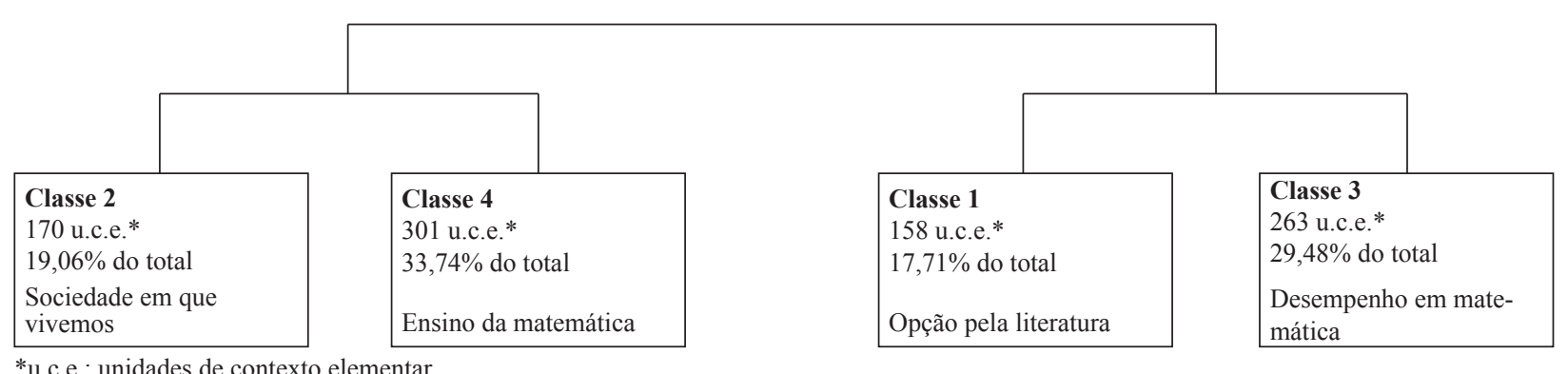

Figura 4. Análise hierárquica descendente corpus 4: eu e a matemática.

A classe 2 se organiza a partir de três palavras: números, através e contato. $\mathrm{O}$ verbo viver também faz parte do vocabulário característico dos participantes que compõem a classe 2. Da leitura desses extratos, observamos que o foco desta classe está baseado na sociedade em que vivemos, a qual está se tornando complexa e necessita de diversas contribuições tecnológicas. Esses sujeitos acreditam que a educação está se adequando à tecnologia que, por sua vez, traz benefícios a diversas áreas do conhecimento. Eles observam que as pessoas e a sociedade se organizam através dos números. Nesse sentido, entendem que a matemática contribui para o desenvolvimento e para o progresso social, cultural e intelectual da humanidade.

Os indivíduos pertencentes a essa classe têm clareza de que estão inseridos numa sociedade em que os números e as estatísticas influenciam a tomada de decisões, mas que não nos damos conta da importância da matemática para o exercício da cidadania. Por outro lado, acreditam que o contato com os números influencia a vida das pessoas e que, a partir do momento em que essas percebem a importância dos conhecimentos matemáticos, seu interesse e curiosidade tendem a aumentar, o que contribui para o aparecimento de novas idéias. Assim, é possível afirmar que essas avaliações contribuiriam para o desenvolvimento de uma atitude positiva em relação à matemática.

Já a classe 4 se organiza através de seis palavras: alunos, raciocínio, resultados, importante, prazer e apaixonada. Os verbos mostrar, resolver, sentir, tentar, saber, buscar, deixar e compreender também fazem parte do vocabulário característico dos que compõem a classe 4. Pela leitura dos extratos, observamos que o foco desta classe está baseado no ensino da matemática, esta considerada como uma "ferramenta importante". Os participantes dessa classe acreditam que os alunos precisam saber resolver um problema, devem aprender a pensar e não somente seguir um modelo para resolver os exercícios propostos.

Esses indivíduos tentam instigar seus alunos a compreender a real importância da matemática. Os representantes dessa classe são apaixonados pela matemática. Quando estão resolvendo problemas matemáticos e chegam ao resultado esperado, sentem uma verdadeira alegria e acreditam que é possível tornar a matemática mais prazerosa. Consideramos que eles avaliam favoravelmente a matemática por meio de julgamentos que podem contribuir para a formação de uma atitude positiva em relação a esse objeto.
A classe 1 se organiza através de três elementos: vestibular, licenciatura e opção (substantivos). Os verbos escolher, continuar, resolver, terminar e ficar também fazem parte do vocabulário característico dos participantes que compõem a classe 1. Pela leitura desses extratos, observamos que o foco da classe 1 está baseado na opção pela licenciatura em matemática. Ao se inscreverem no vestibular, optaram pelo curso por terem tido facilidade em aprender matemática no ensino fundamental e médio e por acreditarem que, no curso superior, teriam a mesma facilidade.

Quando examinamos os extratos relativos à classe 1, observamos que, ao fazerem esta escolha, muitos desses indivíduos se surpreenderam com a licenciatura e desejaram desistir do curso ao iniciá-lo. Embora sentissem dificuldades e soubessem que tinham muito a aprender, alguns deles afirmaram que permaneceriam no curso até sua conclusão. Manifestaram ter persistência nos estudos e que essa característica os fazia aprender muito e seguir gostando cada vez mais de matemática.

Os participantes da classe 1 optaram pela matemática por já exercerem atividades que requeriam conhecimentos matemáticos. Alguns fizeram opção por outros cursos ligados à área das ciências exatas, mas não se identificaram com eles, o que os conduziu para o curso de licenciatura em matemática em que se sentem realizados. Essas manifestações sugerem que os indivíduos pertencentes à classe 1 avaliam favoravelmente o objeto da atitude, pois tendem a se envolver em comportamentos que sustentam o próprio objeto. Essa tendência consciente para a ação permite supor que esse tipo de resposta avaliativa pode contribuir para o desenvolvimento de uma atitude positiva em relação à matemática.

A classe 3 se organiza por meio de sete elementos: série, fundamental, notas, primeira, oitava, quinta e primário. Os verbos tirar, ser, reprovar, dar e lembrar também fazem parte do vocabulário característico dos que compõem esta classe. Pela leitura desses extratos, constatamos que o foco da classe 3 está baseado no desempenho que os participantes apresentam em matemática. O desempenho está relacionado ao próprio esforço e dedicação pessoal no sentido de obter bons resultados ao aprendê-la. O fato de gostar dos professores de matemática que tiveram na educação básica tem ligação com seu envolvimento com esta área do conhecimento. Consequentemente, eles têm bons resultados nas avaliações e passam a se dedicar mais ao estudo da matemática. 
Faria, P. C., Camargo, B. V., \& Moro, M. L. F. (2009). Indicadores de atitude com relação à matemática.

Alguns indivíduos da classe 3 lembram que tiveram êxito na educação básica, por isso passavam a ajudar os colegas nos estudos matemáticos. Para eles, essa situação já se caracterizava como uma ação docente, o que reforçou a vontade de ser professor e a perceber a matemática como uma ciência fascinante. Os sentimentos experimentados por esses indivíduos revelam indícios de uma avaliação positiva do objeto da atitude. Assim, é possível afirmar que o tipo de resposta avaliativa emitida pelos participantes pertencentes à classe 3 estaria contribuindo para o desenvolvimento de uma atitude positiva em relação à matemática.

Em síntese, os resultados da análise do corpus 4 permitem observar que os argumentos utilizados pelos professores com experiência docente de um a dez anos, ao expor sua relação com a matemática, revelam a importância atribuída a essa ciência na sociedade atual: a não compreensão dos conceitos matemáticos dificulta o exercício da cidadania, porque certas pessoas podem se tornar submissas às transações comerciais que realizam no cotidiano por não saberem utilizar devidamente os conceitos matemáticos.

Os argumentos utilizados pelos alunos iniciantes do curso de licenciatura enfatizam a necessidade da compreensão efetiva dos conceitos matemáticos e não somente a memorização e reprodução de procedimentos algorítmicos. Eles se sentem realizados quando resolvem problemas matemáticos e acreditam que poderão ensinar matemática de forma prazerosa.

Ao indicar sua relação com a matemática, certos alunos iniciantes alegaram que fizeram opção pela licenciatura por acreditar que teriam o mesmo desempenho que haviam tido no decorrer da educação básica. Embora tenham se surpreendido com a licenciatura, porque tiveram dificuldades de compreensão dos conceitos abordados logo no início do curso, manifestaram persistência e o desejo de concluir o curso.

Os argumentos utilizados tanto por professores com um a dez anos de experiência quanto por alunos iniciantes, ao identificar seu relacionamento com a matemática, indicam uma avaliação favorável do objeto da atitude e correspondem a marcas ligadas à atitude positiva em relação à matemática.

\section{Discussão}

As informações oriundas dos quatro corpi indicam a existência de alguma relação entre as circunstâncias e a avaliação (favorável ou desfavorável) do objeto da atitude. Com efeito, as razões de escolha do curso superior, os fatores que dificultam o ensino da matemática, as razões que levam a lecioná-la e os relatos autobiográficos que expõem as relações entre ela e os participantes revelam a possibilidade de haver alguma correspondência entre as atitudes para com essa e as circunstâncias em que a pessoa se encontra em determinado momento da vida estudantil ou profissional.

Os resultados da análise quantitativa permitiram ajuizar que, ao ingressar no curso de licenciatura, há mudança de atitude em relação à matemática (de positiva para negativa).
Ao lado disso, conforme resultados do corpus 1, foi possível presumir que uma anterior atitude positiva em relação à matemática contribui para a escolha da licenciatura, mas as experiências vivenciadas logo no início do curso podem mudar esta atitude. No início, há uma diminuição no ânimo para estudar matemática - em função das condições de ensino que encontram -, o que parece relacionado à atitude negativa; ao passo que aqueles que alcançam o final do curso - seja por afinidade para com a matemática ou por empenho em superar as próprias dificuldades de aprendizagem -, começam a almejar a possibilidade do exercício profissional, o que pode estar relacionado à atitude positiva. Ao que tudo indica essas circunstâncias podem contribuir para mudança de atitude em relação à matemática.

Também foi possível verificar uma diferença significativa na atitude dos alunos do início da licenciatura e dos professores em exercício. Os alunos iniciantes do curso de licenciatura apresentaram atitudes negativas. Professores com um a dez anos de experiência apresentaram atitudes positivas. Ao lado disso, de acordo com os resultados do corpus 3, vimos que os professores com um a dez anos de experiência não se diferenciam dos alunos iniciantes quanto ao desejo de lecionar matemática. No entanto, as razões que levaram esses indivíduos a lecionar são divergentes. Os iniciantes do curso manifestaram a predisposição para ensinar matemática de um modo diferente do ensino que haviam recebido na educação básica. Já os professores de um a dez anos alegaram que essa disposição surgiu somente no momento em que começaram a lecionar.

Além disso, de acordo com os resultados do corpus 4, foi possível observar que os professores de um a dez anos de experiência não se diferenciam dos alunos iniciantes quanto à importância da compreensão dos conceitos matemáticos no ensino. Porém, os argumentos utilizados para destacar tal importância também são diferentes, pois os iniciantes do curso enfatizam a necessidade da compreensão efetiva dos conceitos matemáticos e não somente a memorização e reprodução de procedimentos algorítmicos. Já os professores com um a dez anos de experiência enfatizam que a importância da compreensão está ligada à possibilidade do exercício da cidadania.

Os resultados que obtivemos também revelaram que as atitudes em relação à matemática podem modificar-se no transcorrer da atividade profissional: professores com um a dez anos de experiência apresentam atitudes mais positivas que professores com mais tempo de trabalho. De fato, a predisposição para o exercício da docência pode se alterar com o passar do tempo, pois, conforme resultados do corpus 2 , fatores econômicos e sociais também são apontados pelos professores com mais de dez anos de experiência como elementos que dificultam o ensino da matemática. Contribuem para esse resultado fatores como a "falta de recursos didáticos", a "precariedade das escolas", a "marginalização dos jovens" e a "indisciplina dos alunos", os quais podem estar ligados a uma avaliação desfavorável da profissão docente e, consequentemente, da matemática, por parte desses 
professores. Logo, em função do tempo de docência, as atitudes dos professores para com a matemática modificam-se conforme as circunstâncias de um determinado momento da vida profissional.

Ao lado disso, os resultados da entrevista permitiram identificar traços predominantes do conjunto das falas dos cinco participantes com atitudes mais positivas e dos cinco com atitudes mais negativas. Assim, foi possível traçar um perfil de participantes com atitudes as mais positivas, perfil que revela bons sentimentos em relação à matemática e a confiança em um bom desempenho no exercício da docência. Porém, o perfil daqueles com atitudes as mais negativas revela maus sentimentos em relação à matemática e a falta de confiança em um bom desempenho no exercício da docência.

Um dos traços revelados no perfil dos participantes com atitudes mais negativas foi a persistência para concluir o curso. Assim, mesmo tendo apresentado grandes dificuldades durante o curso (provavelmente de aprendizagem), é possível que a conclusão da licenciatura tenha representado uma conquista e ao mesmo tempo um alívio. A possibilidade de entrada no mercado de trabalho, em função de empenho em concluir o curso, pode se apresentar como um fator importante para a mudança de atitude (de negativa para positiva).

Os traços predominantes do perfil dos participantes com atitudes negativas evidenciam que a diferença entre as atitudes dos iniciantes e as dos concluintes também está relacionada às circunstâncias em que se encontram essas pessoas nos respectivos momentos da vida estudantil. No início do curso há uma diminuição no ânimo para estudar matemática, o que parece ligado à atitude mais negativa, ao passo que aqueles que alcançam o final do curso, seja por afinidade com a matemática ou por empenho em superar as próprias dificuldades de aprendizagem, começam a almejar a possibilidade do exercício profissional, algo que estaria relacionado à atitude menos negativa.

Logo, também a condição em que a pessoa se encontra no final da licenciatura e no início da carreira, associada à sua autopercepção de desempenho, denota que a mudança de atitude (de negativa para positiva) está relacionada às particularidades de um determinado momento da vida estudantil ou profissional.

Os resultados desse estudo apontam que há uma correspondência entre a direção de sentimentos, crenças e predisposições, em sentido positivo ou negativo, revelados pelas entrevistas, e o resultado obtido na escala de atitudes.

As informações obtidas com a escala (medida quantitativa de atitude), completadas qualitativamente pela análise dos conteúdos das autobiografias, das entrevistas e questionários permitem verificar congruência entre os traços de cada perfil e as atitudes em relação à matemática. $\mathrm{O}$ uso destes instrumentos permitiu a combinação de dados de ordem quantitativa e qualitativa. Resultados da análise qualitativa de respostas às perguntas abertas de vários instrumentos e de respostas às perguntas da entrevista oral corroboram resultados da análise quantitativa e sugeriram, como vimos, pistas para a explicação da mudança de atitude nos grupos amostrais.
Sem dúvida, então, em estudos dessa natureza, o uso de diversos instrumentos favorece a obtenção de vários indicadores. Tal escolha possibilita ao pesquisador verificar se esses indicadores obedecem a mesma tendência ou não, o que poderá aportar validade aos resultados obtidos.

\section{Referências}

Bardin, L. (1977). Análise de conteúdo. Lisboa: Edições 70. Brito, M. R. F. (1996). Um estudo sobre as atitudes em relação à matemática em estudantes de $1^{\circ}$ e $2^{\circ}$ graus. Tese de livre docência não-publicada, Universidade Estadual de Campinas, Campinas, SP.

Brito, M. R. F. (1998). Adaptação e validação de uma escala de atitudes em relação à matemática. Zetetiké, 6(9), 109-162.

Camargo, B. V. (2005). Um programa informático de análise quantitativa de dados textuais. In A. S. P. Moreira (Org.), Perspectivas teórico-metodológicas em representações sociais (pp. 511-539). João Pessoa: Ed. Universitária da UFPB.

Dobarro, R. V. (2007). Solução de problemas e tipos de mente matemática: Relações com as atitudes e crenças de auto-eficácia. Tese de doutorado não-publicada, Universidade Estadual de Campinas, Campinas, SP.

Doise, W. (2000). Atitudes e representações sociais. In D. Jodelet (Org.), As representações sociais (L. Ulup, Trad., pp. 187-204). Rio de Janeiro: EdUERJ.

Eagly, A. H., \& Chaiken, S. (1993). The psychology of attitudes. Belmont, CA: Wadsworth Group.

Faria, P. C. (1996). A formação do professor de matemática: Problemas e perspectivas. Dissertação de mestrado nãopublicada, Universidade Federal do Paraná, Curitiba, PR.

García, C. (1999). Formação de professores: Para uma mudança educativa. Porto, Portugal: Porto Editora.

Giacomozzi, A. I., \& Camargo, B. V. (2004). Eu confio no meu marido: Estudo da representação social de mulheres com parceiro fixo sobre prevenção da AIDS. Psicologia: Teoria e Prática, 6(1), 31-34.

Gonçalez, M. H. C. C., \& Brito, M. R. F (2001). A aprendizagem de atitudes positivas em relação à matemática. In M. R. F. Brito (Org.), Psicologia da educação matemática: Teoria e pesquisa (pp. 221-233). Florianópolis: Insular.

Likert, R. (1932). A technique for the measurement of attitudes. Archives of Psychology, 22(140), 1-55.

Randel, B., Stevenson, H., \& Witruk, E. (2000). Attitudes, beliefs, and mathematics achievement of german and japanese high school students. International Journal of Behavioral Development, 24, 190-198.

Rodrigues, A. (1981). Psicologia social (9a ed.). Rio de Janeiro: Vozes.

Shiomi, K. (1992). Association of attitudes toward mathematics with self-efficacy, causal attribution, and personality traits. Perceptual and Motor Skills, 75, 563-567.

Silva, C. B., Brito, M. R. F., Cazorla, I. M., \& Vendramini, C. M. M. (2002). Atitudes em relação à estatística e à matemática. Psico-USF, 7, 219-228. 
Trillo, F. (2000). As atitudes dos estudantes: Um indicador da qualidade universitária. In F. Trillo (Org.), Atitudes e valores no ensino (pp. 215-258). Lisboa: Instituto Piaget.

Viana, O. A. (2005). O componente espacial da habilidade matemática de alunos do ensino médio e as relações com o desempenho escolar e as atitudes em relação à matemática e à geometria. Tese de doutorado não-publicada, Universidade Estadual de Campinas, Campinas, SP.

Zan, R., Brown, L., Evans, J., \& Hannula, M. S. (2006). Affect in mathematics education: An introduction. Educational Studies in Mathematics, 63, 113-121.

Paulo Cézar de Faria é Professor Adjunto do Departamento de Matemática da Universidade Federal do Rio Grande do Norte.

Brigido Vizeu Camargo é Professor Associado do Departamento de Psicologia da Universidade Federal de Santa Catarina

Maria Lucia Faria Moro é Professora Titular de Psicologia da Educação, Setor de Educação, da Universidade Federal do Paraná, Professora Sênior do Programa de Pós-graduação em Educação da Universidade Federal do Paraná.

Recebido: $12 / 05 / 2008$

$1^{a}$ revisão: 08/12/2008

$2^{a}$ revisão: 03/03/2009

Aceite final: 23/03/2009 